\title{
MICRO X-RAY FLUORESCENCE IMAGING COUPLED WITH CHEMOMETRICS TO DETECT AND CLASSIFY ASBESTOS FIBERS IN DEMOLITION WASTE
}

\author{
Silvia Serranti ${ }^{1}$, Giuseppe Capobianco ${ }^{1}$, Sergio Malinconico ${ }^{2}$ and Giuseppe Bonifazi 1,* \\ ${ }^{1}$ DICMA, Department of Chemical Engineering, Materials and Environment, Sapienza - University of Rome, via Eudossiana 18, 00184 \\ Rome, Italy \\ ${ }^{2}$ Department of new technologies for occupational safety of industrial plants, products and anthropic settlements, National Institute for \\ Insurance against Accidents at Work, Rome, Italy
}

Article Info:

Received:

21 November 2019

Revised:

28 March 2020

Accepted:

6 May 2020

Available online

30 September 2020

Keywords:

Micro X-ray fluorescence

Asbestos Containing Materials

(ACM)

Asbestos

Demolition waste

\begin{abstract}
Asbestos was largely used in the past by several countries all over the world. From 1900 to 1990 asbestos-containing materials (ACMs) were produced in large amounts and mainly utilized to produce insulation, flame retardant materials, as well as to improve the mechanical and the chemical characteristics of construction materials. Its extensive use has therefore led to the presence of fibers in existing buildings and within the construction and demolition waste. A fast, reliable and accurate recognition of ACMs represents an important target to be reached. In this paper the use of micro X-ray fluorescence (micro-XRF) technique coupled with a statistical multivariate approach was applied and discussed with reference to ACMs characterization. Different elemental maps of the ACMs were preliminary acquired in order to evaluate distribution and composition of asbestos fibers, then samples energy spectra where collected and processed using chemometric methods to perform an automatic classification of the different typologies of asbestos fibers. Spectral data were analyzed using PLS-Toolbox ${ }^{\text {TM }}$ (Eigenvector Research, Inc.) running into Matlab® (The Mathworks, Inc.) environment. An automatic classification model was then built and applied. Results showed that asbestos fibers were correctly identified and classified according to their chemical composition. The proposed approach, based on micro-XRF analysis combined with an automatic classification of the elemental maps, is not only effective and non-destructive, it is fast, and it does not require the presence of a trained operator. The application of the developed methodology can help to correctly characterize and manage demolition waste where ACMs are present.
\end{abstract}

\section{INTRODUCTION}

Asbestos is the common name used for two families of fibrous minerals of different crystallographic and chemical characteristics: serpentine (i.e. chrysotile: $\mathrm{Mg}_{3}\left(\mathrm{Si}_{2} \mathrm{O}_{5}\right)(\mathrm{OH})_{4}$ ) and amphiboles (i.e. crocidolite: $\mathrm{Na}_{2}\left(\mathrm{Fe}^{2+}{ }_{3} \mathrm{Fe}^{3+} 2\right) \mathrm{Si}_{8} \mathrm{O}_{22}(\mathrm{OH})_{2}$ and amosite: $\mathrm{Fe}_{7} \mathrm{Si}_{8} \mathrm{O}_{22}(\mathrm{OH})_{2}$ ) (Lewis et al., 1996; Paglietti et al., 2016). They can all exist in several different crystalline forms, but only if characterized by a fibrous structure are classified as asbestos. The most used mineral in the industrial sector is chrysotile, as it is contained in almost $95 \%$ of all asbestos products and/or artifacts (Virta, R.L., 2005). Among the amphiboles, the most widely used mineral is crocidolite, followed by amosite (Bassani et al., 2007). Asbestos has been widely used in many applications for its technical properties (i.e. resistance to abrasion, heat and chemicals) (Gualtieri, 2017). However, despite its proper- ties, asbestos is recognized as a hazardous material to human health and since 1980 it has been banned in many industrialized countries. The exposition of people to asbestos is quite huge. World Health Organization (WHO) report shows as about 125 million people are exposed to asbestos at the workplace. Every year, asbestos-related-tumors produce the death of about 100,000 people, several thousand related to asbestos exposure at home (Varkey, B., 1983; Olsen et al., 2011). Several solutions were explored to clean up ACMs (Yoshikawa et al., 2015; Zhai et al., 2014; Valouma et a., 2017) but first a preliminary separation of contaminated products from non-hazardous waste is required. Asbestos fibrils are generally very thin and may not all be resolved even by optical magnifications of $400-450 x$, and so, by eye what is seen as fibers are actually bundles of fibers (Harper et al., 2008). On present evidence fiber counts appear to provide a better index of hazard than respirable 
mass concentration. Considerations of respirability and biological activity together suggest that the counts should be of fibers in the size range. In most legislation a "standard" airborne fiber to be counted is a fiber with a lenght greater than 5 micron and width less than 3 micronwith an aspect ratio I/w greater than 3:1. (Walton, W. H.,1984). Asbestos containing material with fibers exposed on degraded surface, can be a possible sources of respirable asbestos fibers. Additionally, fiber identification techniques are crucial for environmental control in contaminated areas such as the proximity of an asbestos mine (Colangelo et al., 2011). The possibility to adopt fast and reliable analysis methods to detect and identify asbestos fibers in laboratory is of great interest in terms of safety, time and costs. Micro-Xray based systems are widely used in different fields of research and it is frequently used as a technique to identify elements in the laboratory and on portable systems. Imaging X Ray fluorescence is the evolution of point micro-XRF and allows to obtain spatial and compositional information simultaneously (Tsuji et al., 2005). This approach is actually applied in many different research areas, as: biology and medicine (Paunesku et al., 2006), cultural heritage (Rosi et al., 2004; Monico et al. 2011; Pronti et al., 2015; Capobianco et al., 2018), forensic research (Dhara et al., 2010; Nakanishi et al. 2008), natural science (Capobianco et al., 2018). In this work, benchtop micro-XRF was utilized to identify and classify asbestos fibers (Bonifazi et al, 2015; Bonifazi et al, 2018). The proposed strategy, based on the combined use of micro-XRF imaging and chemometric techniques, can be a valid and efficient analytical approach supporting the currently adopted asbestos recognition techniques, such as Fourier transform infrared spectroscopy (FT-IR) (De Stefano et al., 2012), Raman spectroscopy (Petriglieri et al., 2015), polarized light microscopy (PLM) (Lee et al., 2008) and scanning electron microscopy (SEM) (Gandolfi et al., 2016). All these techniques require the preparation of samples and usually allow punctual measurements and/ or small areas mapping. The new generation of scanning XRF analytical units, based on confocal XRF method, realizes the best acquisition conditions, both in terms of speed and analytical data set reliability. For every acquired hyper-map, a XRF spectrum is associated to each pixel. Thus, an acquisition consists in a $n \times m$ matrix of spectra, where $\mathrm{n}$ and $\mathrm{m}$ are the number of pixels in the $\mathrm{x}$ and $\mathrm{y}$ direction, respectively (Figueroa et al., 2014). Aim of this work was to verify the possibility to utilize the confocal micro-XRF imaging-based approach as an analytical technique to perform an automatic detection and mapping of asbestos containing materials (ACMs), without the presence of an operator performing a preliminary identification/selection of the different energy ranges/peaks representative of a specific asbestos fiber. The main aim of this procedure was to provide laboratory scale analytical tests allowing the identification of asbestos fibers bundles, following a not-destructive and not-invasive approach automatically carried out. Following this approach it is thus possible to reduce the quantity of samples to be analyzed by classic analytical techniques, that are more sensitive but require a specific samples preparation, longer analytical time and allow the analysis of smaller samples area. Data where thus analyzed by chemometric techniques (exploration and classification methods) and the results compared with the maps of the elements obtainable by the classical approach (i.e. manual selection of the elements associated to each fiber).

\section{MATERIALS AND METHODS}

\subsection{Experimental set up}

Six different ACM samples were investigated, containing 3 different type of asbestos fibers (i.e. chrysotile, crocidolite and amosite) (Figure 1 and Table 1). The ACM fragments were sampled from different contaminated sites by the Department of New Technologies for Occupational Safety of Industrial Plants, Products and Anthropic Settlements, (National Institute for Insurance against Accidents at Work - INAIL). Sample collection was performed following the general guidelines that have to be adopted when asbestos remediation actions have to be performed in superfund sites (INAIL, 2010). XRF analyses according to the rules reported in "Fact Sheet: Recognition and characterization of ACM by micro-XRF" (INAIL, 2020). Selected areas of the sample surfaces were used to acquire the micro-XRF maps. More in details, sample areas of Figures $1 \mathrm{a}, 1 \mathrm{~b}$ and $1 \mathrm{c}$ were utilized to perform calibration, whereas those shown in Figures $1 \mathrm{~d}, 1 \mathrm{e}$ and $1 \mathrm{f}$ were utilized to validate the classification model. The micro-XRF based elements mapping was performed at Raw-Ma Lab (Raw materials Laboratory) - Department of Chemical Engineering, Materials \& Environment (Sapienza - University of Rome, Italy. A benchtop spectrometer (M4 Tornado, Bruker ${ }^{\circledR}$ ), equipped with a Rh X-ray tube with poly-capillary optics as the $\mathrm{X}$-ray convergence technique and XFlash ${ }^{\circledR}$ detector providing an energy resolution better than $145 \mathrm{eV}$ and 5 filters, was utilized (Guerra et al., 2013). The whole spectra comprised 4096 channels with a spot size of approximately $30 \mu \mathrm{m}$. Spectrum energy calibration was daily performed before each analysis batch by using zirconium ( $\mathrm{Zr}$ ) metal (Bruker ${ }^{\circledR}$ calibration standard). The sensitivity of $\mu \mathrm{XRF}$ is determined by the excitation probability of the sample and the peak to background ratio. The background intensities were directly computed by the equipment (ESPRIT Bruker ${ }^{\circledR}$ software). The sample chamber can be evacuated to 25 mbar and, therefore, light elements such as sodium can be measured (Nikonow et al., 2016). Constant exciting energies of $50 \mathrm{kV}$ and $500 \mu \mathrm{A}$, were adopted for acquisition. The set-up mapping acquisition parameters were a pixel size of $30 \mu \mathrm{m}$ and an acquisition time, for each pixel, of 10 milliseconds. Through this experimental set-up is possible to map bundles of asbestos fiber inside matrix until a resolution of 30 micron in a wide scanning area (max acquisition area $19 \times 16 \times 12 \mathrm{~cm}$ for each sample). Spectral data (i.e. hyper-maps) analysis was carried out adopting chemometric methods, using the PLS_Toolbox (version 8.6, Eigenvector Research, Inc.) running inside MATLAB (version 9.3, The Mathworks, Inc.). Starting from the samples outlined in Figure 1, two mosaic data images were built (Figure 2) in order to define the calibration (Figure 2a) and validation (Figure 2b) data set. 

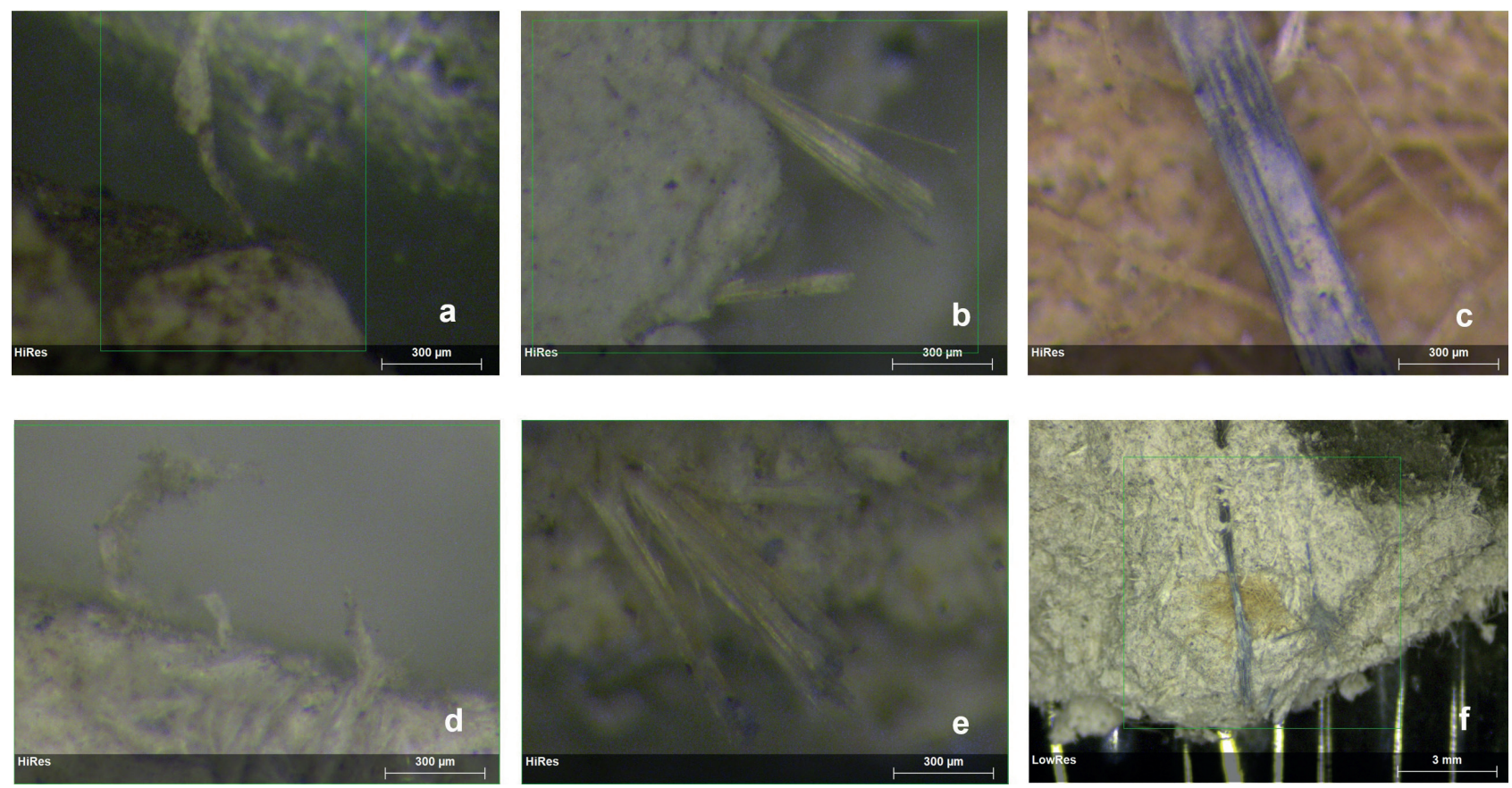

FIGURE 1: Asbestos containing materials (ACM) microscopic images: chrysotile (a and d), amosite (b and e) and crocidolite (c and f). Sample images $\mathrm{a}, \mathrm{b}$ and $\mathrm{c}$ have been utilized for calibration and $\mathrm{d}$, $\mathrm{e}$ and $\mathrm{f}$ for validation.
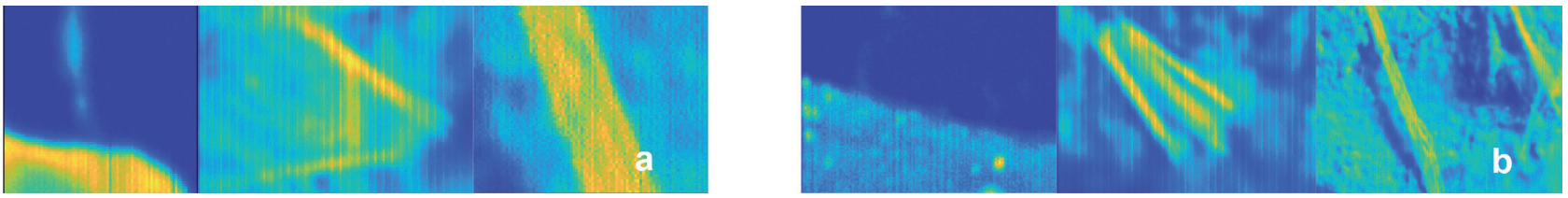

FIGURE 2: Mosaic data image of ACM samples used for calibration (a) and validation (b) dataset, respectively. a: mosaic image obtained by the combination of the images reported in Figure 1a, $1 \mathrm{~b}$ and $1 \mathrm{c}$. b: mosaic image obtained by the combination of the images reported in Figure $1 \mathrm{~d}, 1 \mathrm{e}$ and $1 \mathrm{f}$.

\section{$2.2 \mu \mathrm{XRF}$ : acquisition and data handling}

The experimental procedure was defined and implemented in two steps. The 1 st step was finalized to the acquisition of the hyper-maps and the further XRF peaks deconvolution in order to identify the different asbestos minerals following the classical expert-based approach. The 2nd step was addressed to energy spectra acquisition and handling to define an "automatic" chemometric based classification model.

\subsubsection{Step 1: hyper-maps acquisition and XRF peak decon- volution}

ACM samples were acquired by $\mu \mathrm{XRF}$ in order to build, as already mentioned, the element maps. Specific Areas in the Sample (SAS) of the ACM were then analyzed in order

TABLE 1: Asbestos samples selected to perform the XRF based recognition/classification procedures.

\begin{tabular}{l:l} 
Samples & Description \\
\hline Samples containing chrysotile & Fragment of corrugated sheets (Materit) \\
\hdashline Samples containing amosite & Fragment of flat slab (Materit) \\
\hline Samples containing crocidolite & Fragment of a water tank \\
\hline
\end{tabular}

to quantify the element concentration and identify asbestos fibers (Figure 3).

2.2.2 Step 2: Definition of the calibration dataset and identification of elements by soft independent modelling by class analogy (SIMCA)

Calibration dataset were acquired by micro-XRF to build an automatic classification model able to recognize the different asbestos fibers without any human based investigation. A set of 3 asbestos fibers clearly identified in the ACM samples was used as training dataset to build the classification model (Figure 2a). The classification model was then validated utilizing the ACM samples (Figure $2 b$ ). Spectral data analysis was preliminary addressed to explore and to evaluate the quality of the acquired information to be utilized for the further classification model definition, design, implementation and set up. To reach these goals, a preliminary Principal Component Analysis (PCA) and a further Soft Independent Modelling by Class Analogy (SIMCA) was applied. PCA is the most utilized multivariate data analysis method for exploratory data handling, outlier detection, rank (dimensionality) reduction, graphical clustering, classification, regression, etc. (Bro et al., 2014). It 

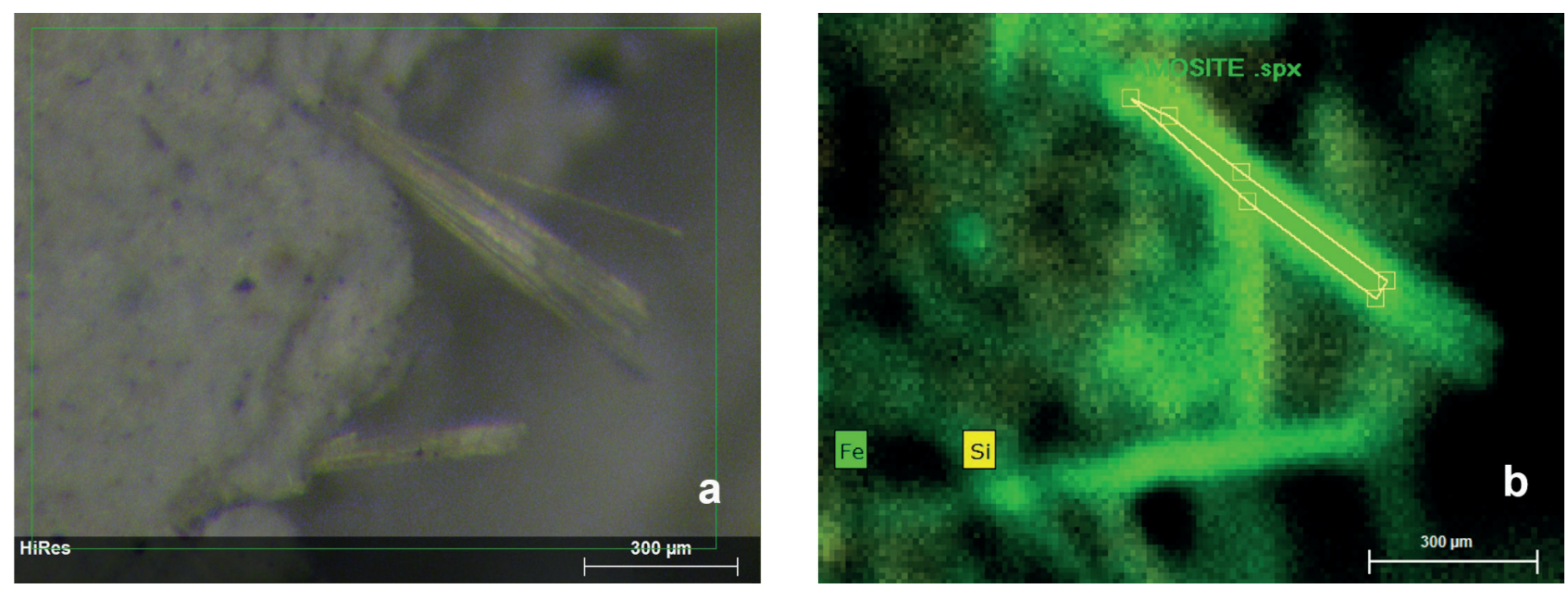

FIGURE 3: Example of procedure adopted to identify asbestos minerals with reference to amosite. a: source image and b: corresponding Fe and Si maps, where a Specific Areas in the Sample (SAS) was selected in order to verify, through the corresponding energy spectra deconvolution, the qualitative and semi-quantitative element presence, characteristic of the target asbestos mineral (i.e. amosite).

was used to decompose the "pre-processed" spectral data into several principal components (PCs) (linear combinations of the original spectral data) embedding the spectral variations of each collected spectral data set. According to this approach, a reduced set of factors is produced and used for discrimination, since it provides an accurate description of the entire dataset. The first few PCs, resulting from PCA, are generally utilized to analyze the common features among samples and their grouping: samples characterized by similar spectral signatures tend to aggregate in the score plot of the first two or three components. Spectra could be thus characterized either by the reflectance at each wavenumber in the wavenumber space, or by their score on each PC in the PC space (Bro et al., 2014). Samples characterized by similar spectra, belonging to the same class of products, are grouped in the same region of the score plot related to the first two or three PCs, whereas samples characterized by different spectral features will be clustered in other parts of this space. Starting from PCA, different energy spectra pre-processing was sequentially applied, that is: Baseline, for spectra background subtraction, Normalize and Probabilistic Quotient Normalization (PQN), for spectra normalization and, finally, Mean centering (MC).

SIMCA is one of the most commonly used class modelling techniques for the classification of spectral data with many applications in different sectors, such as pharmaceutical (Celli et al., 2018), food (Nieuwoudt et al., 2004), biology (Oust et al., 2004) and medicine (Krafft et al., 2006). In SIMCA based modelling unknown samples are compared to the PCA class models and assigned to the class according to their analogy with the calibration samples (Brereton, 2003). SIMCA classifies objects into the category whose principal component model best reproduces the data. Only data points which are members of a given category are used in determining the model functions for that category. The importance of each feature in classification is determined by its contribution to the category covariance matrices. Therefore, once the model is obtained, it can be applied to an entire hypercube and for the classification of new hypercubes. The result of SIMCA, applied to the hyperspectral images, is a "prediction map," where the class of each pixel can be identified using color mapping.

The confusion matrix, reporting the Positive Predictive Value, Negative Predictive Value, Accuracy, False Discovery Rate and False Omission Rate, was also computed in order to evaluate the quality of the model. The possible results in prediction being: True Positive (TP), that is asbestos spectrum correctly identified, False Positive (FP), that is asbestos spectrum incorrectly identified, True Negative (TN), that is asbestos spectrum correctly rejected and False Negative (FN), that is asbestos spectrum incorrectly rejected. The quality of prediction results can be evaluated taking into account the values of Sensitivity, Specificity, Positive and Negative Predictive Value, False Discovery Rate, False Omission Rate and Accuracy parameters obtained for the classification model. Sensitivity measures the proportion of actual positives that are correctly identified as such, while, Specificity measures the proportion of actual negatives that are correctly identified as such (Sharma et al., 2009). Positive and Negative Predictive Values are the proportions of positive and negative results in statistics and diagnostic tests that are true positive and true negative results, respectively (Fletcher et al., 2012). The False Discovery Rate is the proportion of the spectra with a known positive condition for which the test result is negative (Lage-Castellanoset al., 2010). False Omission Rate measures the proportion of false negatives which are incorrectly rejected (Lage-Dresselhaus al., 2002). Accuracy is the degree of correspondence of the theoretical data with the real data (Linnet al., 2012). Other parameters have been also computed, they are reported in the following, that is:

$$
\text { sensitivity is calculated using the following formula: }
$$$$
\text { Sensitivity }=T P /(T P+F N)
$$ 
- specificity is calculated using the following formula:

Specificity $=\mathrm{TN} /(\mathrm{TN}+\mathrm{FP})$

positive predictive value is calculated using the following formula:

Positive predictive value $=\mathrm{TP} /(\mathrm{TP}+\mathrm{FP})$

negative predictive value is calculated using the following formula:

Negative predictive value $=\mathrm{TN} /(\mathrm{TN}+\mathrm{FN})$

false discovery rate is calculated using the following formula:

False discovery rate $=\mathrm{FP} /(\mathrm{FP}+\mathrm{TP})$

false omission rate is calculated using the following formula:

False omission rate $=\mathrm{FN} /(\mathrm{FN}+\mathrm{TN})$

- accuracy is calculated using the following formula:

Accuracy $=(\mathrm{TP}+\mathrm{TN}) /(\mathrm{P}+\mathrm{N})$

\section{RESULTS AND DISCUSSION}

Results and discussion are reported in the following, presenting and comparing the classical human based micro-XRF mapping approach and the proposed automatic one based on SIMCA classification.

\subsection{Element maps of asbestos fibers}

The results of the semi-quantitative analysis, as resulting from energy spectra deconvolution, are summarized in Table 2, in terms of detected elements inside the different
SAS. As shown in Table 2, the SAS analysis of fibers detected on the map allows to identify the elements with the highest concentration and their relative ratios. Light elements with low mean concentration (i.e. sodium) were not detected in map mode probably due to the reduced acquisition pixel per time (i.e. 10 milliseconds).

The chrysotile spectrum was characterized by a $\mathrm{Mg}$ concentration greater than those belonging to amosite and crocidolite. The amosite shows a higher Fe concentration than that detected in crocidolite. Crocidolite spectrum is characterized by the presence of Fe and small quantity of $\mathrm{Mg}$. These physical characteristics and their relative values are useful but not sufficient enough to define the presence of asbestos fibers in the complex matrix. The elemental maps of the examined samples shown in Figure 4, summarize the complexity of the analyzed data. For this reason, in order to isolate the spectral signatures of the different fibers and to use them to create a predictive model, a PCA of the identified fibers was carried out. The results shown in Table 2 are not the typical compositions of pure asbestos minerals like chrysotile, amosite or crocidolite. The elements as Calcium (Ca), Aluminium (Al), Sulfur (S), Potassium $(\mathrm{K})$, copper $(\mathrm{Cu})$ and Titanium $(\mathrm{Ti})$, were related to the matrix. The spectral compositions of the asbestos fibers shown in Table 2 was influenced by the surrounded matrix of the demolition waste material. As a consequence, in order to obtain a representative calibration dataset for the classification model, it was necessary to use asbestos fibers coming from fiber of different types of waste product containing ACM.

TABLE 2: Results of the semi-quantitative determination carried out by Energy Dispersive micro-XRF on ACM samples chracterized by a cement matrix.

\begin{tabular}{|c|c|c|c|c|c|c|c|c|c|c|c|c|}
\hline \multirow[b]{2}{*}{ 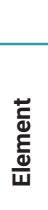 } & \multicolumn{2}{|c|}{ Chrysotile (A) } & \multicolumn{2}{|c|}{ Amosite (B) } & \multicolumn{2}{|c|}{ Crocidolite (C) } & \multicolumn{2}{|c|}{ Chrysotile (D) } & \multicolumn{2}{|c|}{ Amosite (E) } & \multicolumn{2}{|c|}{ Crocidolite (F) } \\
\hline & 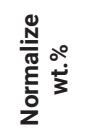 & 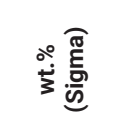 & 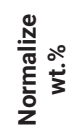 & 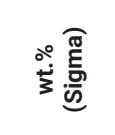 & 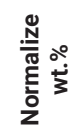 & 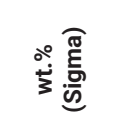 & 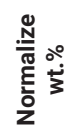 & 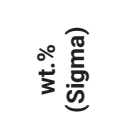 & 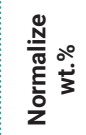 & 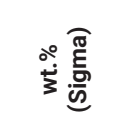 & 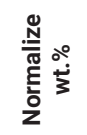 & 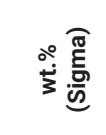 \\
\hline $\mathrm{Ca}$ & 52.79 & 2.17E-02 & 30.49 & 8.79E-02 & 53.41 & 1.19E-01 & 22.28 & $1.55 \mathrm{E}-03$ & 10.93 & 3.57E-03 & 44.60 & 7.85E-02 \\
\hline $\mathrm{Si}$ & 29.84 & $3.28 \mathrm{E}-02$ & 21.27 & 2.04E-01 & 13.52 & $3.78 \mathrm{E}-02$ & 37.50 & 1.76E-02 & 7.05 & $7.72 \mathrm{E}-03$ & 16.79 & 5.77E-02 \\
\hline $\mathrm{Fe}$ & 2.55 & 7.08E-05 & 41.54 & 1.47E-01 & 27.93 & 2.92E-02 & 5.56 & $1.04 \mathrm{E}-04$ & 74.90 & $1.38 \mathrm{E}-01$ & 32.21 & 3.79E-02 \\
\hline $\mathrm{Mg}$ & 9.11 & $5.84 \mathrm{E}-03$ & 1.06 & 2.43E-03 & 2.65 & 2.92E-03 & 15.51 & $5.81 \mathrm{E}-03$ & 0.13 & $1.08 \mathrm{E}-04$ & 3.38 & 4.01E-03 \\
\hline Al & 3.27 & 8.39E-04 & 0.26 & 2.13E-04 & 1.02 & 4.40E-04 & 2.58 & 2.73E-04 & 0.02 & $6.39 \mathrm{E}-06$ & 1.10 & 4.93E-04 \\
\hline$S$ & 0.42 & 1.57E-05 & 1.18 & 7.82E-04 & 0.71 & 1.32E-04 & 10.25 & $1.38 \mathrm{E}-03$ & 0.11 & $5.40 \mathrm{E}-06$ & 1.05 & $2.44 \mathrm{E}-04$ \\
\hline$P$ & 1.29 & 5.39E-05 & 0.45 & 6.77E-05 & 0.23 & $9.68 \mathrm{E}-06$ & 1.51 & 3.85E-05 & 0.18 & $6.46 \mathrm{E}-06$ & 0.25 & $9.09 \mathrm{E}-06$ \\
\hline $\mathrm{Ti}$ & 0.24 & 2.93E-06 & 0.12 & $6.48 \mathrm{E}-06$ & 0.15 & $2.74 \mathrm{E}-06$ & 2.00 & 2.47E-05 & 0.02 & $1.84 \mathrm{E}-07$ & 0.16 & $2.40 \mathrm{E}-06$ \\
\hline $\mathrm{Mn}$ & 0.16 & $1.21 \mathrm{E}-06$ & 3.45 & $1.23 \mathrm{E}-03$ & 0.08 & $1.20 \mathrm{E}-06$ & 0.21 & $1.18 \mathrm{E}-06$ & 6.22 & $1.14 \mathrm{E}-03$ & 0.08 & 8.89E-07 \\
\hline $\mathrm{Sr}$ & 0.02 & $9.68 \mathrm{E}-08$ & 0.13 & $6.57 \mathrm{E}-06$ & 0.15 & $2.44 \mathrm{E}-06$ & 0.05 & $3.18 \mathrm{E}-07$ & 0.39 & 1.49E-05 & 0.14 & $1.90 \mathrm{E}-06$ \\
\hline $\mathrm{Zn}$ & 0.01 & $5.76 \mathrm{E}-08$ & 0.00 & $1.22 \mathrm{E}-07$ & 0.06 & $6.15 \mathrm{E}-07$ & 2.38 & 2.69E-05 & 0.03 & $5.02 \mathrm{E}-07$ & 0.14 & $1.49 \mathrm{E}-06$ \\
\hline $\mathrm{Cr}$ & 0.05 & 3.31E-07 & 0.03 & $1.06 \mathrm{E}-06$ & 0.04 & 4.81E-07 & 0.18 & $9.41 \mathrm{E}-07$ & 0.01 & 5.61E-08 & 0.03 & $2.68 \mathrm{E}-07$ \\
\hline $\mathrm{P}$ & 0.24 & $1.18 \mathrm{E}-05$ & - & - & - & - & - & - & - & - & 0.01 & $3.79 \mathrm{E}-07$ \\
\hline $\mathrm{Cu}$ & - & - & - & - & 0.04 & 3.15E-07 & - & - & 0.03 & 2.19E-06 & 0.05 & 3.75E-07 \\
\hline
\end{tabular}



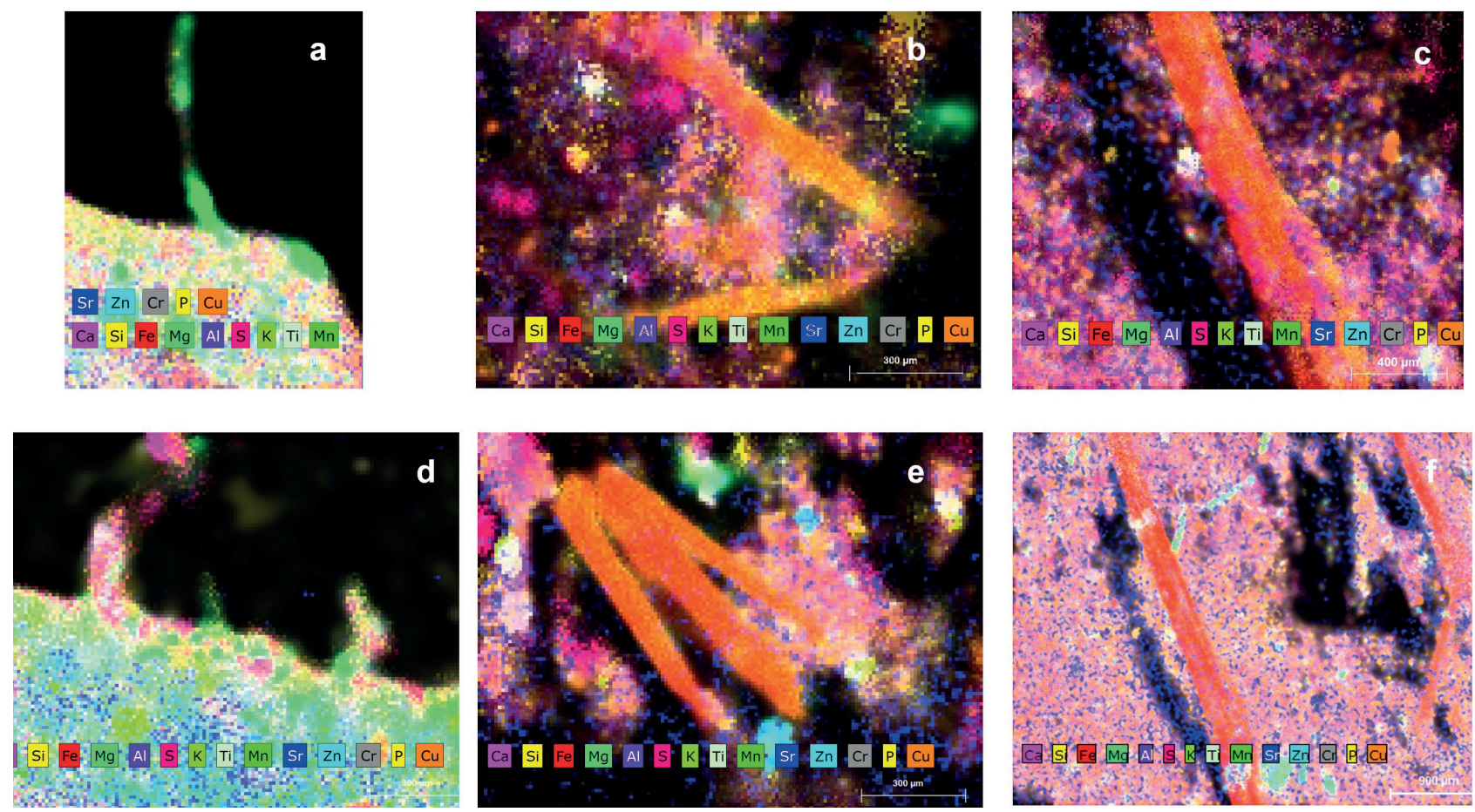

FIGURE 4: Elemental maps as resulting from the micro-XRF analysis carried out on samples. In detail chrysotile (a and d), amosite (b and e) and crocidolite (c and f).

\subsection{PCA of calibration samples and identification of fibers by SIMCA}

The energy spectra resulting from calibration are characterized by several peaks according to the emission of a photon quantum (fluorescence radiation), related to the energy difference between samples inner and outer shell. To emphasize the spectral characteristics of all the detected elements, "only" the mean spectra between 0 and $10 \mathrm{KeV}$ have been considered, processed and mean centered (Figures $5 a$ and 5 ), before the application of preprocessing.

A mosaic procedure was applied to obtain a single hypercube for calibration dataset. To emphasize the difference between the various peaks, the following pre-processing were used before the application of PCA: Baseline, Normalize, PQN and MC (Figure $6 \mathrm{a}$ and $6 \mathrm{~b}$ ).

The PCA score plot allows identifying three distinct groups according to their spectral signature. The score plot
(PC1-PC2) reported in Figure 7a shows a good separation (i.e. distinction) of all the elements, as well as a good uniformity for each class. The loadings of PC1, PC2 (Figure 7b) show, in the region between $1.1 \mathrm{KeV}$ and $7 \mathrm{KeV}$, the high variance of data, as a consequence 3 principal components are necessary to explain the $93.78 \%$ of the calibration dataset variance.

The selected energy spectra have been thus adopted as training dataset and a SIMCA model was built. The obtained values of sensitivity and specificity are shown in Table 3. The Sensitivity estimates the model ability to measure the number of samples of a given type correctly classified as that type. The specificity estimates the model ability to measure the number of samples not of a given type correctly classified as not of that type. Sensitivity and specificity can be assumed as model efficiency indicators: the more the values are close to one, the better the modelling is. In this study, the obtained values for sensitivity and
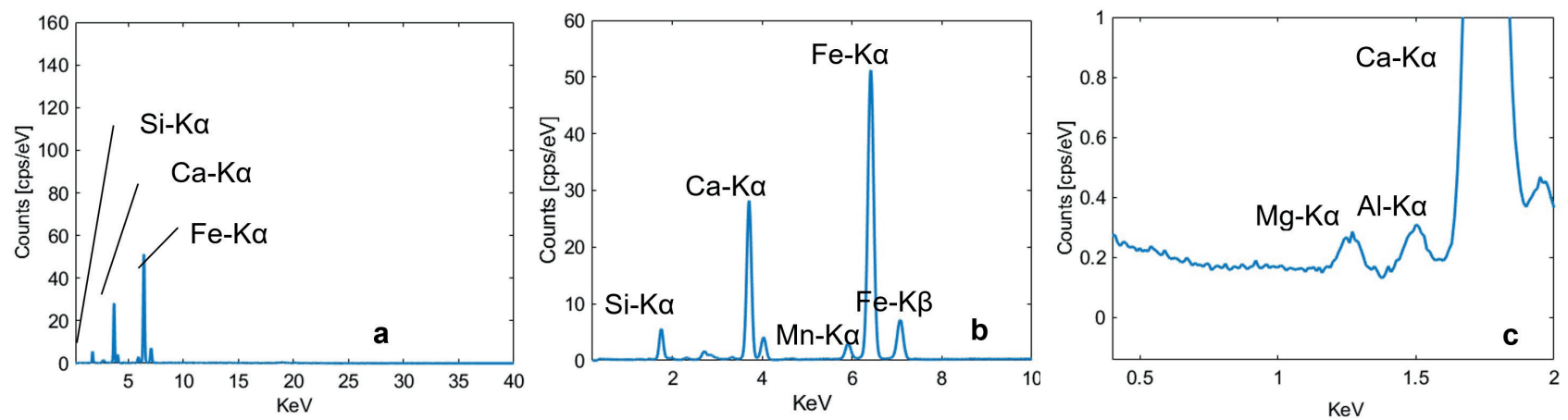

FIGURE 5: Raw energy spectrum of a generic SAS, before (a) and after (b) channels selection (i.e. 0-10 KeV). Detail of Mg Ka spectra area (c). 

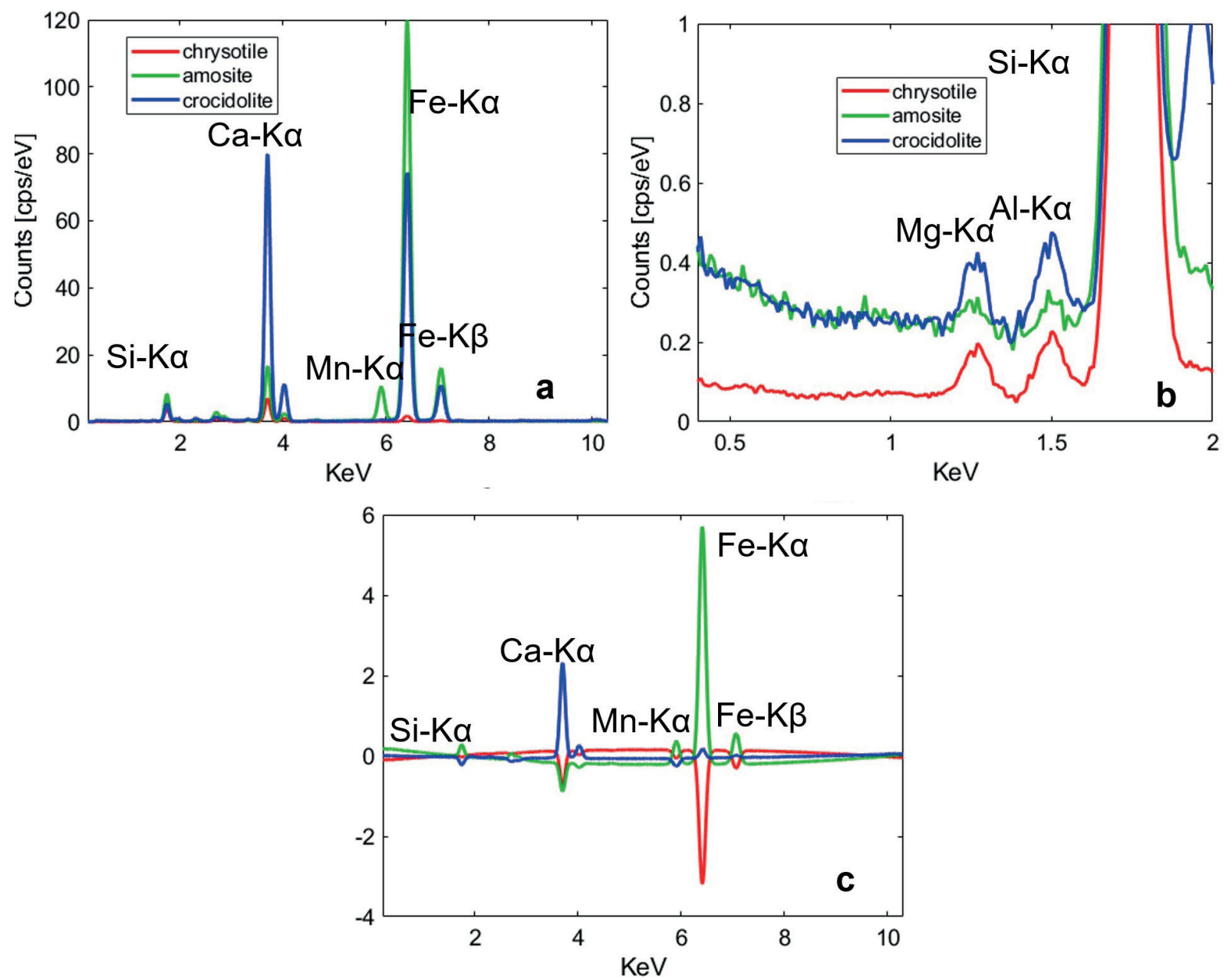

FIGURE 6: Raw (a), detail of Mg Ka spectra area (b) and pre-processed spectra (c), as resulting from the sequential application of different pre-processing algorithms: PQN, Baseline (Automatic Weighted Least Squares), Normalize and Mean Center.
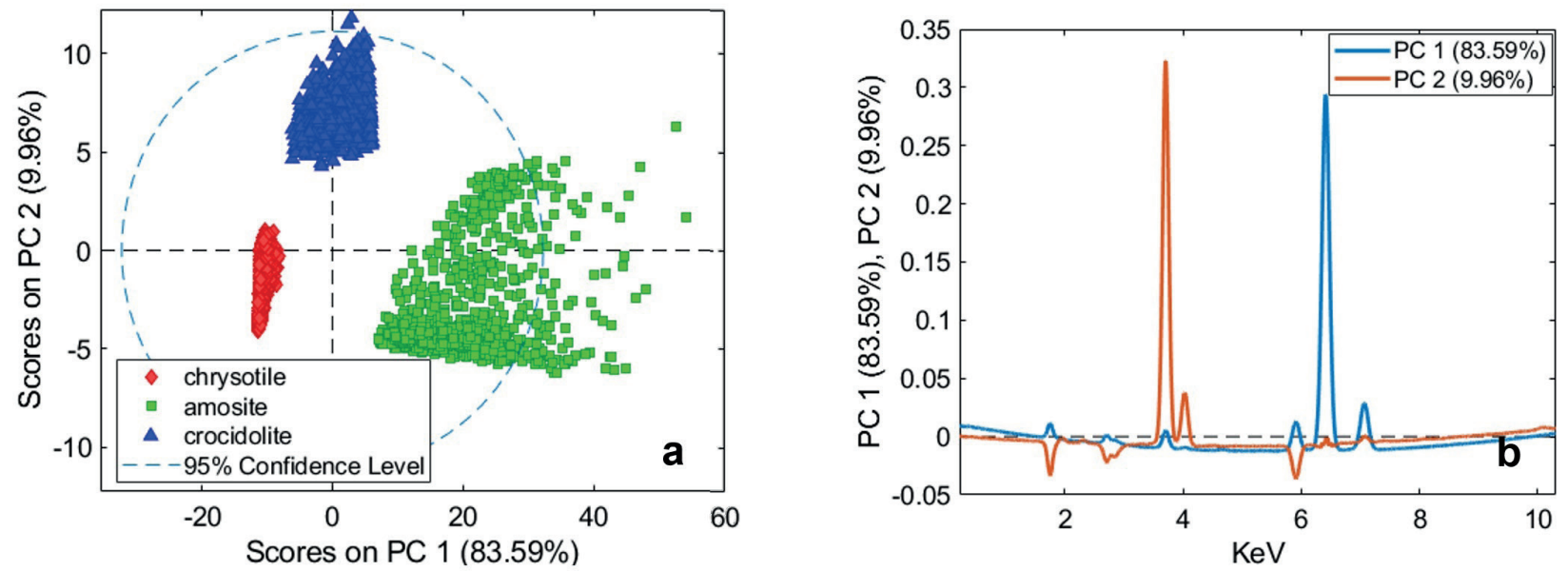

FIGURE 7: PCA score plot (a) e loading plot (b) of calibration dataset.

specificity are very good. To verify its classification ability, the built SIMCA model was applied to the validation of ACM samples data set. Sensitivity and specificity also in validation assume high values (Table 3 ).

The results in terms of prediction (i.e. "Pred Probability") are shown in Figure 8: the class with the highest prob- ability belongs to the asbestos. The obtained results are very good for all the investigated elements, being comparable with those obtained following the classical "instrument-men-driven" approach. Misclassifications sometimes occur, but they are mainly due to border effect. The prediction of the chrysotile is good. Chrysotile fibers are well iden- 
TABLE 3: Sensitivity and specificity for the SIMCA based built model. Cal: calibration; CV: cross-validation and PRED: prediction.

\begin{tabular}{|c|c|c|c|}
\hline & Chrysotile & Amosite & Crocidolite \\
\hline Sensitivity (Cal) & 1.00 & 0.98 & 1.00 \\
\hline Specificity (Cal) & 0.99 & 1.00 & 1.00 \\
\hline Sensitivity(CV) & 0.84 & 0.85 & 0.90 \\
\hline Specificity (CV) & 1.00 & 1.00 & 1.00 \\
\hline Sensitivity (PRED) & 0.84 & 0.99 & 0.82 \\
\hline Specificity (PRED) & 0.99 & 0.88 & 1.00 \\
\hline
\end{tabular}

tified, despite the presence of high noise due to the uneven surface characteristics (i.e. de-focusing effect). The identification of amosite and crocidolite is also quite satisfactory. Only few pixels are misclassified.

The results of the confusion matrix in prediction are shown in Table 4. They show good a predictive capability of the model with a value of Positive and Negative Predictive Value closer to one and never under 0.86.

The low value of False Discovery and Omission Rate highlights the low number of spectra which are incorrectly classified with a range value between 0.01 and 0.14 . In general, the Accuracy of each asbestos class prediction were over 0.91 .

\section{CONCLUSIONS}

The study was carried out to investigate the utilization of chemometric procedures, based on processing of data-
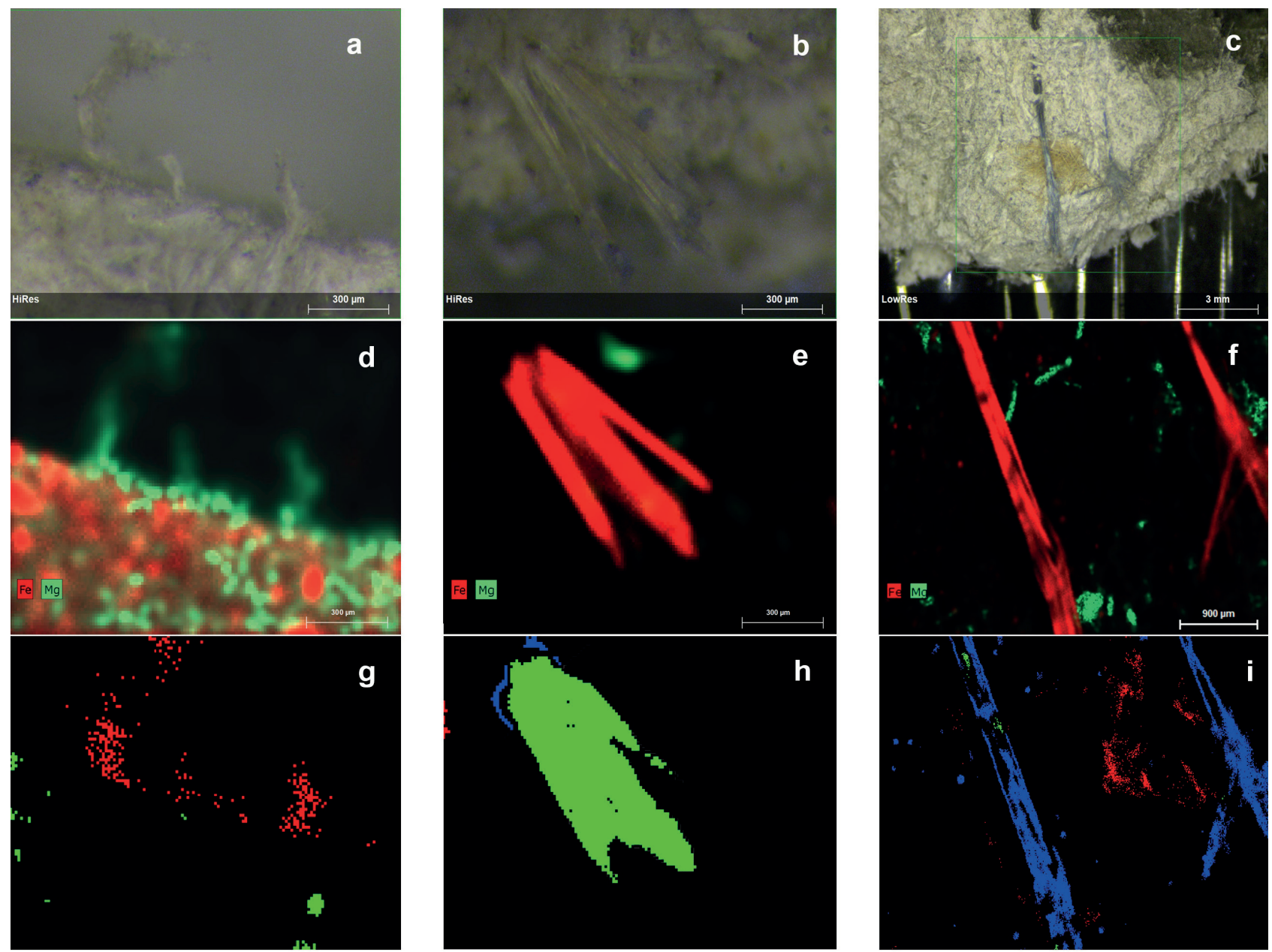

- Class Pred Member chrysotile

- Class Pred Member amosite

- Class Pred Member crocidolite

FIGURE 8: Microscope image of the ACM samples: chrysotile (a), amosite (b) and crocidolite (c). Micro-XRF map of iron and magnesium referred to chrysotile (d), amosite (e) and crocidolite (f). SIMCA prediction results obtained for chrysotile (g), amosite (h) and crocidolite (i). 
TABLE 4: Positive predictive value, negative predictive value, accuracy, false discovery rate and false omission rate for the SIMCA prediction results.

\begin{tabular}{|c|c|c|c|}
\hline & Chrysotile & Amosite & Crocidolite \\
\hline Positive Predictive Value & 0.99 & 0.89 & 0.99 \\
\hline Negative Predictive Value & 0.86 & 0.99 & 0.84 \\
\hline Accuracy & 0.92 & 0.94 & 0.91 \\
\hline False Discovery Rate & 0.01 & 0.11 & 0.01 \\
\hline False Omission & 0.84 & 0.99 & 0.82 \\
\hline Rate & 0.14 & 0.01 & 0.16 \\
\hline
\end{tabular}

set generated by micro-XRF, in order to perform a preliminary laboratory scale automatic check on the presence of asbestos fibers in cement matrix. More in detail, SIMCA, after PCA, was applied to build a model able to recognize/ classify asbestos fibers starting from the reference energy spectra representative of the different asbestos minerals. The proposed combined chemometric micro-XRF approach presents many advantages: it is objective, and the classification model does not require an expert user for the interpretation of results. In fact, the final output of the model was a false color map assigning a color for each asbestos type. In the future, using a robust calibration dataset, this procedure could be applied to different anthropogenic ACM waste materials at laboratory scale in order to reduce the quantity of material to be analyzed with consolidated analytical techniques, requiring both sample preparation and longer analysis time. The procedure, after the preliminary model recognition set up, is easy to implement and it is characterized by low operative costs, being the procedure totally software, especially if compared with classical methods usually requiring sample pre-treatment and longer analytical time (i.e. optical microscopy and SEM-EDX). Further studies will be addressed to a systematic application of asbestos recognition in order to perform not only a qualitative control of the different ACM samples, but also to characterize different types of asbestos fibers in different types of matrix. Following this approach, it will be thus possible to design more efficient and specialized strategies for the identification of asbestos fibers using imaging XRF techniques.

\section{ACKNOWLEDGEMENTS}

The study was developed in the framework of INAIL (National Institute for Insurance against Accidents at Work) project: BRIC ID 58 - P9 Asbestos special program.

\section{REFERENCES}

Bassani, C., Cavalli, R. M., Cavalcante, F., Cuomo, V., Palombo, A., Pascucci, S., \& Pignatti, S. (2007). Deterioration status of asbestoscement roofing sheets assessed by analyzing hyperspectral data. Remote Sensing of Environment, 109(3), 361-378.

Bonifazi, G., Capobianco, G., \& Serranti, S. (2015, November). Hyperspectral imaging applied to the identification and classification of asbestos fibers. In 2015 IEEE SENSORS (pp. 1-4). IEEE.

Bonifazi, G., Capobianco, G., \& Serranti, S. (2018). Asbestos containing materials detection and classification by the use of hyperspectral imaging. Journal of hazardous materials, 344, 981-993.

Brereton, R. G. (2003). Chemometrics: data analysis for the laboratory and chemical plant. John Wiley \& Sons.
Bro R. and Smilde A. K. (2014). Principal component analysis. Analytical Methods, 6(9), 2812-2831.

Capobianco, G., Brunetti, P., Bonifazi, G., Costantino, P., Cardarelli, M., \& Serranti, S. (2018). The use of micro-energy dispersive X-ray fluorescence spectrometry ( $\mu$-XRF) combined with a multivariate approach to determine element variation and distribution in tobacco seedlings exposed to arsenate. Spectrochimica Acta Part B: Atomic Spectroscopy, 147, 132-140.

Capobianco, G., Pelosi, C., Agresti, G., Bonifazi, G., Santamaria, U., \& Serranti, S. (2018). X-ray fluorescence investigation on yellow pigments based on lead, tin and antimony through the comparison between laboratory and portable instruments. Journal of Cultural Heritage, 29, 19-29.

Celli, G. B., Selig, M. J., Tan, C., \& Abbaspourrad, A. (2018). Synergistic Bathochromic and Hyperchromic Shifts of Anthocyanin Spectra Observed Following Complexation with Iron Salts and Chondroitin Sulfate. Food and bioprocess technology, 11(5), 991-1001.

Colangelo, F., Cioffi, R., Lavorgna, M., Verdolotti, L., \& De Stefano, L. (2011). Treatment and recycling of asbestos-cement containing waste. Journal of hazardous materials, 195, 391-397.

De Stefano, L., Cioffi, R., \& Colangelo, F. (2012). Comparison between two FT-IR spectroscopy analytical procedures for micrograms determination of asbestos species in bulk materials. American Journal of Analytical Chemistry, 3(01), 1.

Dhara, S., Misra, N. L., Maind, S. D., Kumar, S. A., Chattopadhyay, N., \& Aggarwal, S. K. (2010). Forensic application of total reflection $\mathrm{X}$-ray fluorescence spectrometry for elemental characterization of ink samples. Spectrochimica Acta Part B: Atomic Spectroscopy, 65(2), 167-170.

Dresselhaus, T. R., Luck, J., \& Peabody, J. W. (2002). The ethical problem of false positives: a prospective evaluation of physician reporting in the medical record. Journal of medical ethics, 28(5), 291-294.

Figueroa, R. G., Lozano, E., Belmar, F., Alcaman, D., Bohlen, A., Oliveira, C. A. B., Silva, A.L.M. \& Veloso, J.F.C.A. (2014). Characteristics of a robust and portable large area $\mathrm{X}$-ray fluorescence imaging system. X-Ray Spectrometry, 43(2), 126-130.

Fletcher, R. H., Fletcher, S. W., \& Fletcher, G. S. (2012). Clinical epidemiology: the essentials. Lippincott Williams \& Wilkins.

Gandolfi, N. B., Gualtieri, A. F., Pollastri, S., Tibaldi, E., \& Belpoggi, F. (2016). Assessment of asbestos body formation by high resolution FEG-SEM after exposure of Sprague-Dawley rats to chrysotile, crocidolite, or erionite. Journal of hazardous materials, 306, 95-104.

Gualtieri, A.F. (Eds.), EMU Notes in Mineralogy, Mineral fibres: crystal chemistry, chemical-physical properties, biological interaction and toxicity, Volume 18, 2017, 7-9.

Guerra, M. B. B., Schaefer, C. E., de Carvalho, G. G., de Souza, P. F., Júnior, D. S., Nunes, L. C. and Krug, F. J. (2013). Evaluation of micro-energy dispersive $\mathrm{X}$-ray fluorescence spectrometry for the analysis of plant materials. Journal of Analytical Atomic Spectrometry, 28(7), 1096-1101.

Harper, M., Lee, E. G., Doorn, S. S., \& Hammond, O. (2008). Differentiating non-asbestiform amphibole and amphibole asbestos by size characteristics. Journal of occupational and environmental hygiene, 5(12), 761-770.

INAIL, (2010). Linee guida generali da adottare durante le attività di bonifica da amianto nei siti da bonificare di interesse nazionale, (https:// www.inail.it/cs/internet/docs/decalogo_bonifiche_amianto_2010pdf.pdf?section=attivita). 
INAIL, (2020), Fact sheet: riconoscimento e caratterizzazione di materiali contenenti amianto mediante microfluorescenza a raggi $\mathrm{X}$. ISBN 978-88-7484-176-9

Krafft, C., Shapoval, L., Sobottka, S. B., Geiger, K. D., Schackert, G., \& Salzer, R. (2006). Identification of primary tumors of brain metastases by SIMCA classification of IR spectroscopic images. Biochimica et Biophysica Acta (BBA)-Biomembranes, 1758(7), 883-891.

Lage-Castellanos, A., Martínez-Montes, E., Hernández-Cabrera, J. A., \& Galán, L. (2010). False discovery rate and permutation test: an evaluation in ERP data analysis. Statistics in medicine, 29(1), 63-74.

Lee, R. J., Strohmeier, B. R., Bunker, K. L., \& Van Orden, D. R. (2008). Naturally occurring asbestos-a recurring public policy challenge. Journal of Hazardous materials, 153(1-2), 1-21.

Lewis, I. R., Chaffin, N. C., Gunter, M. E., \& Griffiths, P. R. (1996). Vibrational spectroscopic studies of asbestos and comparison of suitability for remote analysis. Spectrochimica Acta Part A: Molecular and Biomolecular Spectroscopy, 52(3), 315-328.

Linnet, K., Bossuyt, P. M., Moons, K. G., \& Reitsma, J. B. (2012). Quantifying the accuracy of a diagnostic test or marker. Clinical chemistry, 58(9), 1292-1301.

Monico, L., Van der Snickt, G., Janssens, K., De Nolf, W., Miliani, C., Verbeeck, J., ... \& Cotte, M. (2011). Degradation process of lead chromate in paintings by Vincent van Gogh studied by means of synchrotron X-ray spectromicroscopy and related methods. 1. Artificially aged model samples. Analytical chemistry, 83(4), 12141223.

Nakanishi, T., Nishiwaki, Y., Miyamoto, N., Shimoda, O., Watanabe, S., Muratsu, S., ... \& Suzuki, S. (2008). Lower limits of detection of synchrotron radiation high-energy $\mathrm{X}$-ray fluorescence spectrometry and its possibility for the forensic application for discrimination of glass fragments. Forensic science international, 175(2-3), 227234.

Nieuwoudt, H. H., Prior, B. A., Pretorius, I. S., Manley, M., \& Bauer, F. F. (2004). Principal component analysis applied to Fourier transform infrared spectroscopy for the design of calibration sets for glycerol prediction models in wine and for the detection and classification of outlier samples. Journal of agricultural and food chemistry, 52(12), 3726-3735

Nikonow, W. and Rammlmair, D. (2016). Risk and benefit of diffraction in Energy Dispersive X-ray fluorescence mapping. Spectrochimica Acta Part B: Atomic Spectroscopy, 125, 120-126.

Olsen, N. J., Franklin, P. J., Reid, A., de Klerk, N. H., Threlfall, T. J., Shilkin, K., \& Musk, B. (2011). Increasing incidence of malignant mesothelioma after exposure to asbestos during home maintenance and renovation. Medical Journal of Australia, 195(5), 271-274.
Oust, A., Møretrø, T., Kirschner, C., Narvhus, J. A., \& Kohler, A. (2004). FT-IR spectroscopy for identification of closely related lactobacilli. Journal of Microbiological Methods, 59(2), 149-162.

Paglietti, F., Malinconico, S., Conestabile della Staffa, B., Bellagamba, S., \& De Simone, P. (2016). Classification and management of asbestos-containing waste: European legislation and the Italian experience. Waste management, 50, 130-150.

Paunesku, T., Vogt, S., Maser, J., Lai, B., \& Woloschak, G. (2006). X-ray fluorescence microprobe imaging in biology and medicine. Journal of cellular biochemistry, 99(6), 1489-1502

Petriglieri, J. R., Salvioli-Mariani, E., Mantovani, L., Tribaudino, M., Lottici, P. P., Laporte-Magoni, C., \& Bersani, D. (2015). Micro-Raman mapping of the polymorphs of serpentine. Journal of Raman Spectroscopy, 46(10), 953-958.

Pronti, L., Felici, A. C., Alesiani, M., Tarquini, O., Bracciale, M. P., Santarelli, M. L., ... \& Piacentini, M. (2015). Characterisation of corrosion layers formed under burial environment of copper-based Greek and Roman coins from Pompeii. Applied Physics A, 121(1), 59-68.

Rosi, F., Miliani, C., Borgia, I., Brunetti, B., \& Sgamellotti, A. (2004). Identification of nineteenth century blue and green pigments by in situ $x$-ray fluorescence and micro-Raman spectroscopy. Journal of Raman Spectroscopy, 35(8-9), 610-615

Sharma, D., Yadav, U. B., \& Sharma, P. (2009). The concept of sensitivity and specificity in relation to two types of errors and its application in medical research. Journal of Reliability and Statistical studies, 2(2), 53-58.

Tsuji, K., Injuk, J., \& Van Grieken, R. (Eds.). (2005). X-ray spectrometry: recent technological advances. John Wiley \& Sons.

Valouma, A., Verganelaki, A., Tetoros, I., Maravelaki-Kalaitzaki, P., \& Gidarakos, E. (2017). Magnesium oxide production from chrysotile asbestos detoxification with oxalic acid treatment. Journal of hazardous materials, 336, 93-100.

Varkey, B. (1983). Asbestos exposure: An update on pleuropulmonary hazards. Postgraduate medicine, 74(4), 93-103.

Virta, R. L. (2005). Mineral Commodity Profiles, Asbestos (p. 56). Circular 1255-KK. Reston, VA: US Geological Survey.

Walton, W. H. (1982). The nature, hazards and assessment of occupational exposure to airborne asbestos dust: a review. The Annals of occupational hygiene, 25(2), 117-119.

Yoshikawa, N., Kashimura, K., Hashiguchi, M., Sato, M., Horikoshi, S. Mitani, T., \& Shinohara, N. (2015). Detoxification mechanism of asbestos materials by microwave treatment. Journal of hazardous materials, 284, 201-206.

Zhai, W., Wang, Y., Deng, Y., Gao, H., Lin, Z., \& Li, M. (2014). Recycling of asbestos tailings used as reinforcing fillers in polypropylene based composites. Journal of hazardous materials, $270,137-143$ 